\title{
Cooperation of SMEs - Empirical Evidences After the Crisis
}

\author{
Jens Schütze, Heiko Baum, Martina Ganß, Ralica Ivanova, and Egon Müller \\ Chemnitz University of Technology, \\ Institute of Industrial Management and Factory Systems, \\ Department of Factory Planning and Factory Management, \\ 09107 Chemnitz, Germany \\ \{jens.schuetze, heiko.baum, martina.ganss, ralica.ivanova, \\ egon.mueller\} @mb.tu-chemnitz.de \\ http: //www.tu-chemnitz.de/mb/FabrPlan/Englisch/
}

\begin{abstract}
Cooperation is a key success factor for small and medium enterprises (SME) in most of the countries. At the beginning of the 2000s, a large European study has analysed the extent and the effect of cooperation between SMEs. However, how successful have been cooperation of SMEs during the economic crisis of the last years? Has the cooperation rate decreased or increased? What are the drivers and obstacles of SME cooperation? Based on an empirical study in a SME-rich region in Germany, which was finished in January 2011, these and further questions will be answered in detail.
\end{abstract}

Keywords: Cooperation, Small and Medium Enterprise, Empirical Study, Collaborative Network, Virtual Breeding Environment.

\section{Introduction}

SMEs are a crucial economic factor in nearly every country in this world [1]. This fact has been recognized by the European Union at an early stage. In order to improve the monitoring of the economic development of SMEs and consequently to offer political support for the SME-sector, which is important in terms of economic policy, but also has a weak lobbying, the Observatory of European SMEs has been created in December 1992 by the European Commission, and replaced in 2008 by the SME Performance Review.

However, the effort of this analysis of the SME-sector is enormous. Due to the legal form and the size only limited statistical data on SME are available (e.g. from business registers and tax authorities), SME-analyses are often conducted in the form of interviews with the companies. For example, in the 2007 Observatory survey more than 17,000 SMEs were interviewed over the telephone within one month EU-wide [2].

Although the scientific discipline of the Collaborative Networks $(C N)$ has been well established in the meantime [3] and cooperation is considered essential especially for SME [4], only little empirical data on cooperation in SMEs is existent. In 2003, the extent and the effect of cooperation between European SMEs were 
analysed in a large-scale study [5]. Unfortunately, this research line was not continued. Most of the following empirical analysis by the Observatory of European SMEs and the SME Performance Review have not reflected cooperative aspects. In addition, other SME-analyses, like the British CBR SME Survey [6] or the Canadian Stats Link SME Report [7], hardly allowed any conclusions on cooperative questions in SMEs. The only reliable access to empirically based data marks case studies in collaborative networks of SME (e.g. [8], [9]).

In light of this, it appeared meaningful to conduct a survey on cooperation in SMEs and especially to include the experiences during the global economic and financial crises of 2007 to 2010. In the following, a survey about German SMEs will be presented dealing with this problem.

\section{The SMEflex Survey}

SMEflex is a German collaborative research project dealing with the stabilityconducive use of flexibility strategies in SME. ${ }^{1}$ The project started in autumn 2009 and first gained a wide range of established flexibility approaches, which are mentioned in the literature. 50 internal and 74 external flexibility instruments had been identified and were clustered in seven groups. One of these flexibility groups comprised all kinds of cross-company collaboration. ${ }^{2}$

The survey was carried out from September 2010 to January 2011 in 131 SMEs. It was designed as a multi-hour personal interview with the company owner, the executive board or the upper management level (e.g. chief financial officer). The surveyed enterprises belong to the following industrial sectors and regions:

- Mechanical and plant engineering in the region East Germany

- High performance composite materials in the federal state of Saxony-Anhalt

- Precision technology and precision engineering in the federal state of Saxony

- Renewably energies in the federal state of Berlin-Brandenburg

All size ranges of SMEs were surveyed ${ }^{3}:$ (1) micro-enterprises with a maximum of 9 employees and an annual turnover of up to 2 million Euro, (2) small enterprises with a maximum of 49 employees and an annual turnover of up to 10 million Euro as well as (3) medium-sized enterprises with a maximum of 249 employees and an annual turnover of up to 50 million Euro (balance sheet total of up to 43 million Euro). Due to country-specific characteristics and on the basis of the SME definition given by the German Institute for SME Research [13], additional another size range of SMEs was surveyed: (4) medium-sized enterprises with a maximum of 499 employees and an annual turnover of up to 50 million euro (balance sheet total of up to 43 million Euro). For comparative purpose, two large scale enterprises (LSEs) were surveyed too. The questionnaire was tested and improved in all four sectors and regions.

\footnotetext{
${ }^{1}$ The research agenda of the project is described in [10].

${ }^{2}$ Details on the flexibility groups can be found in [11]. The present article focuses only on cross-company collaboration.

${ }^{3}$ According to the EU definition of SMEs [12].
} 


\section{Empirical Results}

\subsection{Extent of SME Cooperation}

As the EU-study of 2003 [5] already stated, the extent of cooperation is subject to considerable country-specific differences. Whilst nearly $70 \%$ of all SMEs in Finland cooperated, it was only $10 \%$ in Portugal. The cooperation rate in German SMEs totalled at less than $30 \%$ according to this study [5:24].

Compare to that, the SMEflex survey of 2010/11 shows a strong increase in the cooperation rate since $2003-72 \%$ of the surveyed SMEs stated that they are cooperating. It is striking that the extent of cooperation correlates with the enterprise size. Whilst only up to $46 \%$ of the micro-enterprises participate in cooperation, already up to $67 \%$ of the small enterprises and up to $82 \%$ of the medium-sized enterprises act likewise. The cooperation rate in medium-sized enterprises with more than 250 employees (German SME definition, see chapter 2) and large scale enterprises, mounted up to $100 \%$ (figure 1).

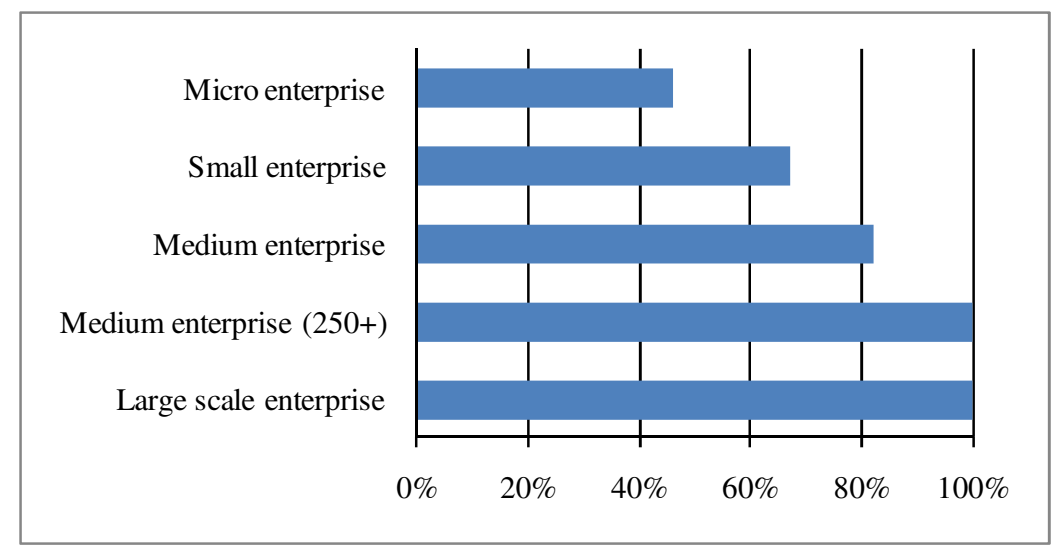

Fig. 1. Cooperation rate in German SMEs $(n=131+2)$

\subsection{Objectives of SME Cooperation}

The objectives enterprises associate with cooperation are exceedingly multifaceted. Table 1 outlines the pursued objectives. Altogether, a large percentage of SME cooperation aims at economic aspects: By cooperating, 61\% of the SMEs aim at improving their profitability, 59\% at using synergies, $51 \%$ at achieving cost reductions and $47 \%$ at saving time. Market-oriented objectives are in second place: By cooperating, 56\% of the SMEs would like to enter new markets, $42 \%$ want to create new market strengths or improve their negotiating position and $24 \%$ target on overcoming market and mobility barriers. Further objectives like representation of interests and risk splitting only play a subordinate role. 
Table 1. Reasons for SME cooperation $(n=94)$

\begin{tabular}{lc}
\hline & Percentage of SMEs* \\
\hline Improve profitability & $62 \%$ \\
Use of synergies & $61 \%$ \\
Entering new markets & $55 \%$ \\
Realising qualitative competitive advantages & $54 \%$ \\
Cost reduction & $51 \%$ \\
Optimisation of the value-added chain & $49 \%$ \\
Time-savings & $48 \%$ \\
Taking up activities not realisable by the power of a single enterprise & $46 \%$ \\
Create market strength/improve negotiating position & $43 \%$ \\
Representation of interests & $35 \%$ \\
Changing market and mobility barriers & $24 \%$ \\
Risk splitting & $19 \%$ \\
Remedying competitive situation & $17 \%$ \\
Prestige reasons & $15 \%$ \\
Unification and standardisation of inter-company procedures & $13 \%$ \\
Others & $15 \%$ \\
\hline
\end{tabular}

* Multiple answers allowed

A better qualification of the employees, development of new products, improve customer loyalty, creating fixed relationships and gaining information on trends and tendencies of the industry at an early stage were named as other aims. The categories used in the EU-study of 2003 [5] are apparently not sufficient to cover the entire range of cooperation objectives. ${ }^{4}$

\subsection{Drivers of SME Cooperation}

Which factors have had a positive influence on the cooperation with other SMEs? This central question documents the actual experiences made by the SMEs whilst cooperating (Table 2) and is a major factor in providing support for Virtual Breeding Environments and finally CN creation [14].

The achieved know-how profit is pointed out as a positive effect by $54 \%$ of the enterprises. When cooperating, already existing business relationships are considered advantageous by $51 \%$ of the SMEs and $43 \%$ associate an improved corporate image with cooperation. Likewise, $43 \%$ of the surveyed SMEs improved their market position by cooperating, whilst $31 \%$ observed rationalisation effects and $21 \%$ a more efficient business organisation in their enterprises. If there is no existent business relationship between the cooperating partners so far, $27 \%$ found it advantageous to have a structural similarity between the partners and $16 \%$ preferred a similar organisational culture. A reduced risk of non-productive time could be observed by $11 \%$ of the SMEs. Only $2 \%$ of the surveyed SMEs were not able to detect any positive factors occurring out of cooperation. Confidence, a reduction of the processing time and an advance in new technologies were named as other drivers.

${ }^{4}$ The following objectives were differentiated: access to new and bigger markets, to expanded procurement options for products, access to know-how and technologies, additional production capacities, lower costs, access to labour, access to capital and others [5:19]. 
Table 2. Enhancers of SME cooperation ( $n=94)$

\begin{tabular}{lc}
\hline & Percentage of SMEs* \\
\hline Achieving know-how profit & $55 \%$ \\
Already existing business relationships & $51 \%$ \\
Improved image of the own company & $43 \%$ \\
Improved market position & $43 \%$ \\
Rationalisation effects & $32 \%$ \\
Structural similarities of the partners & $28 \%$ \\
More efficient business organisation & $21 \%$ \\
Similar business culture & $16 \%$ \\
Reduced risk of non-productive time & $12 \%$ \\
Others & $15 \%$ \\
No enhancers & $2 \%$ \\
\hline
\end{tabular}

* Multiple answers allowed

\subsection{Obstacles to SME Cooperation}

Of course, it is important as well to name those factors that could negatively affect cooperation or maybe even avoid their initiation. The answers documented in Table 3 exclusively result from companies that already took part in cooperation, i.e. have own experiences. The apprehensions of non-cooperating SMEs are not included.

Basically, two important categories can be recognised: organisational and confidence barriers. The following barriers can be counted among the category organisation: $31 \%$ of the surveyed SMEs considered the organisational effort emerging from cooperation to be negative and $20 \%$ stated longer decision-making times because of the cooperation. The category confidence is considerably more multifaceted: $25 \%$ of the companies rated arising dependencies as a barrier, $22 \%$ had difficulties in finding appropriate cooperation partners, $20 \%$ were afraid to lose knowhow, $10 \%$ feared unequal power distribution between the cooperation partners, $8 \%$ worried about an opportunistic behaviour of a cooperation partner, $8 \%$ criticised a lack of communication and $7 \%$ a lack of confidence. $18 \%$ of the surveyed SMEs

Table 3. Barriers to SME cooperation $(n=94)$.

\begin{tabular}{lc}
\hline & Percentage of SMEs* \\
\hline Organisational effort & $31 \%$ \\
Arising dependencies & $25 \%$ \\
Difficulties in finding appropriate cooperation partners & $21 \%$ \\
Fear of losing know-how & $20 \%$ \\
Longer decision-making times & $19 \%$ \\
Fear of unequal power distribution between the cooperation partners & $11 \%$ \\
Fear of opportunistic behaviour of a cooperation partner & $9 \%$ \\
Lack of communication & $9 \%$ \\
Lack of confidence & $7 \%$ \\
Unclear advantage of the cooperation & $7 \%$ \\
Others & $4 \%$ \\
No barriers & $18 \%$ \\
\hline
\end{tabular}

* Multiple answers allowed 
observed no cooperation barriers and the advantage of the cooperation was not clear to $7 \%$ of the companies. In comparison to the EU-study "SME and cooperation", a similar categorisation of the cooperation barriers could be detected, even though the prioritisation of the factors is, to some extent, considerably varying [5:36].

\subsection{SME Cooperation and Competitive Strength}

In the SMEflex survey, it was attempted to evaluate how the competitive strength of an SME is influenced by cooperation. "The measurement of the relationship between SME co-operation and competitive strength is complex, ambiguous and difficult" [5:33] already found the ENSR Survey 2003.

Thus, in a first step the SMEs were asked according to their satisfaction in relation to introduction, achievement, employee acceptance, business benefit and crisis aptitude (Figure 2).

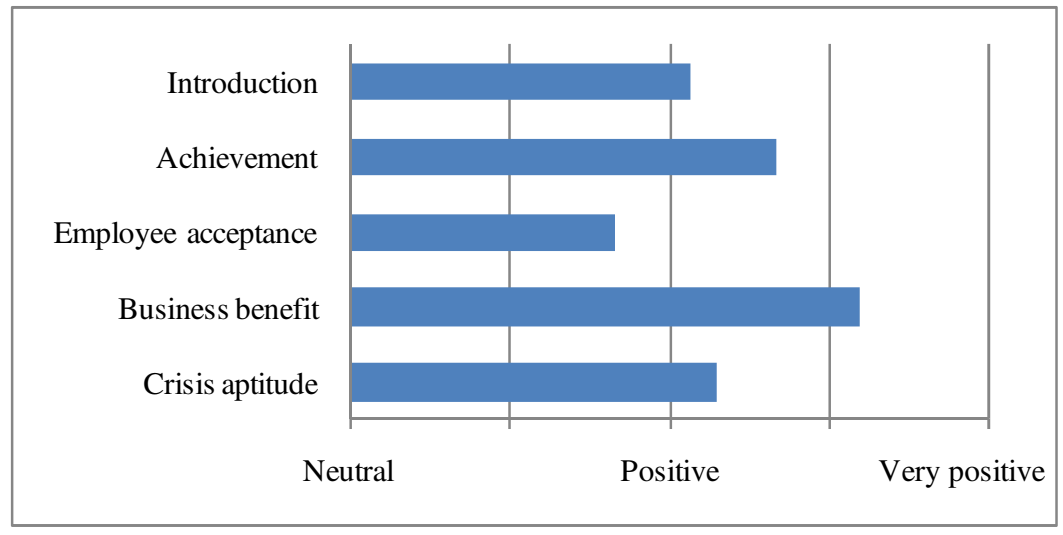

Fig. 2. Satisfaction with cooperation $(n=94)$

Since these statements are subjective and tends to be too positive after recovery from crisis, additionally the staff acquisition was analysed. As shown in Figure 3, the percentage of SMEs with staff inflow in 2009 was in the cooperating enterprises significantly higher than in those without staff acquisition ( $76 \%$ vs. $52 \%$ ).

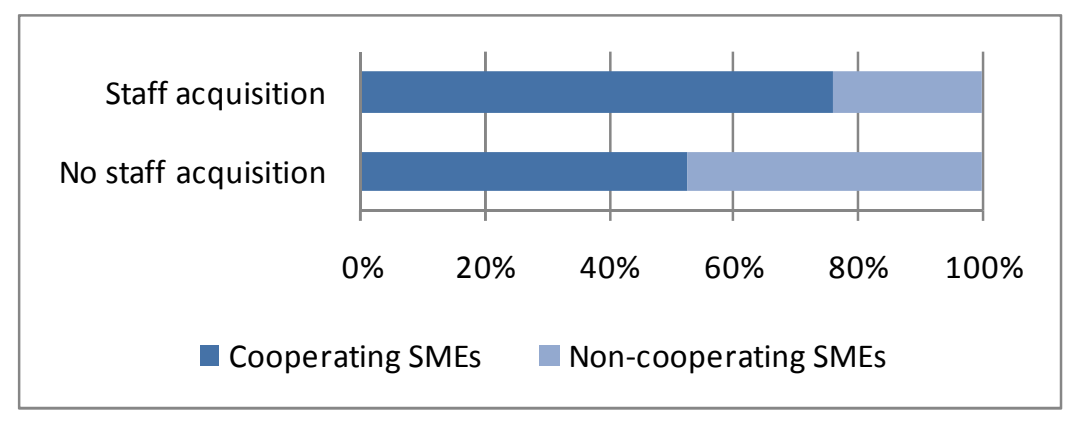

Fig. 3. Staff acquisition in SME during $2009(n=116)$ 


\section{Conclusions}

This report provides an overview of the current (post-crisis) situation in the SME sector of East Germany. It could only be given a brief outline. However, even these few empirically-based data show the importance of cooperation for SMEs and what factors contribute to help or hinder the creation process of cooperation. A consolidated view indicates that the smaller the company, the more potential there is for cooperation.

Therefore, the creation of a cooperative milieu, particular in regions with a high share of $\mathrm{SMEs}^{5}$, is crucial to their economic survival. The approaches from the European FP6 ECOLEAD project or the German Collaborative Research Center 457 „Non-hierarchical Regional Production Networks” provide a sound base for this but need a stronger policy support.

A deeper analysis of the empirical data with multivariate statistics is envisaged as the project continues.

Acknowledgments. This work has been supported by the German Federal Ministry of Education and Research (BMBF) and the European Social Funds (ESF) under grant number 01FH09147. It has been developed in the scope of the German research project SMEflex (www.smeflex.info) and the European WORK-IN-NET Coordination Action (www.workinnet.org). The authors also thank the contributions from their partners.

\section{References}

1. Ayyagari, M., Beck, T., Demirguc-Kunt, A.: Small and medium enterprises across the globe. Small Business Economics 29, 415-434 (2007)

2. European Commission: Flash Eurobarometer 196 - Observatory of European SMEs. Analytical Report, The Gallup Organization, Brussels (2006)

3. Camarinha-Matos, L., Afsarmanesh, H.: Collaborative networks - a new scientific discipline. Journal of Intelligent Manufacturing 16(4-5), 439-452 (2005)

4. Müller, E. (ed.): Ergebnisbericht des Sonderforschungsbereiches SFB 457 "Hierarchielose regionale Produktionsnetze" (Final report of the Collaborative Research Center CRC 457 "Non-hierarchical Regional Production Networks"), Chemnitz University of Technology (2007)

5. European Commission: Observatory of European SMEs No. 2003/5 "SMEs and Co-operation", Office for Official Publications of the European Communities, Luxembourg (2004)

6. Cosh, A., Hughes, A., Bullock, A., Milner, I.: SME finance and innovation in the current economic crisis: The 2008 Survey. Centre for Business Research, University of Cambridge (2009)

7. White, J.: 2009 SME Check-up - Surviving the Crisis, GDSourcing - Stats Link Canada (2009)

\footnotetext{
${ }^{5}$ Just like East Germany.
} 
8. Baldo, F., Rabelo, R.J.: A Structured Approach for Implementing Virtual Organization Breeding Environments in the Mold and Die Sector: A Brazilian Case Study. In: Camarinha-Matos, L.M., Boucher, X., Afsarmanesh, H. (eds.) PRO-VE 2010. IFIP AICT, vol. 336, pp. 197-203. Springer, Heidelberg (2010)

9. Botarelli, M., Taticchi, P., Cagnazzo, L.: The Virtual Development Office Framework for Business Networks: A Case Study from the Umbrian Packaging District. In: CamarinhaMatos, L.M., Picard, W. (eds.) Proceedings of 9th IFIP Working Conference on Virtual Enterprises, Pervasive Collaborative Networks, Poznan, Poland, September 8-10, pp. 611618 (2008)

10. Schütze, J., Baum, H., Müller, E.: Flexibility Strategies in Small and Medium Enterprises - Discussion of Research Perspectives. In: Proceedings of the 20th International Conference on Flexible Automation and Intelligent Manufacturing - FAIM 2010, July 1214, pp. 364-370. California State University, Oakland (2010)

11. Müller, E., Schütze, J., Baum, H., Ganß, M., Ivanova, R.: Business Flexibility in Small and Medium Enterprises - An Empirical Study. In: Proceedings of the 21th International Conference on Flexible Automation and Intelligent Manufacturing - FAIM 2011, Taichung, Taiwan, June 26-29 (accepted, 2011)

12. European Commission: Commission Recommendation (2003/361/EC) of 6 May 2003 concerning the definition of micro, small and medium-sized enterprises, Official Journal of the European Union, L 124/36, Brussels (2003)

13. Günterberg, B., Wolter, H.J.: Unternehmensgrößenstatistik 2001/2002 - Daten und Fakten (Company size statistics 2001/2002 - Facts and Figures). In: Institut für Mittelstandsforschung Bonn (ed.): IfM-Materialien Nr. 157, Bonn (2003)

14. Galeano, N., Guerra, D., Irigoyen, J., Molina, A.: Virtual Breeding Environment - A First Approach to Understand Working and Sharing Principles. In: Konstantas, D., Bourrières, J.P., Léonard, M., Boudjlida, N. (eds.) Proceedings of INTEROP-ESA 2005, Interoperability of Enterprise Software and Applications, Geneva, Switzerland, February 23-25, pp. 99-110 (2006) 